\title{
Optimizing the Dual Band Multi Frequency Microstrip Antenna Using Fractal Geometry
}

\author{
Ashish A. Dixit ${ }^{1}$, Dr. Ved Vyas Dwivedi ${ }^{2}$,Hitesh Mathukiya ${ }^{3}$ \\ ${ }^{1}$ (E.C. Department, C.U. Shah College of Engineering \& Technology, Gujarat, India) \\ ${ }^{2}$ (Pro-vice Chancellor, C.U. Shah University, Gujarat, India) \\ ${ }^{3}$ (E.C. Department, C.U. Shah College of Engineering \& Technology, Gujarat, India)
}

\begin{abstract}
In this paper the Sierpinski Carpet based fractal microstrip antenna with zero, first and second iterations is implemented. Fractal antenna has been extensively investigated because of its multiband operation and compact size. This paper presents a fractal based antenna using Sierpinski carpet geometry. A simple microstrip antenna with the zero iteration, first iteration and the second iteration Sierpinski carpet fractal antenna were designed and optimized. The simple microstrip antenna obtains a return loss of $-29.22 d B$ at the resonant frequency of $2.46 \mathrm{GHz}$. The first iteration Sierpinski carpet fractal antenna provides a return loss of

$-31.04 \mathrm{~dB}$ at the resonant frequency of $2.2 \mathrm{GHz},-14.79 \mathrm{~dB}$ at $3.803 \mathrm{GHz}$ and $-19.81 \mathrm{~dB}$ at $4.3580 \mathrm{GHz}$. The second iteration Sierpinski carpet fractal antenna resonates at $2.19 \mathrm{GHz}, 3.79 \mathrm{GHz}$, and $4.38 \mathrm{GHz}$ with return loss of $-25.69 \mathrm{~dB},-14.30 \mathrm{~dB},-19.60 \mathrm{~dB}$ respectively. In this paper patch volume reduced up to $20.85 \%$ and also we obtain optimum VSWR \& return loss. The substrate material is FR4 epoxy with dielectric constant 4.4 .Entire design implemented and simulated on HFSS-13.
\end{abstract}

Keywords: Fratcal geometry, HFSS, Microstrip antenna, Sierpinski carpet, VSWR

\section{INTRODUCTION}

The very rapid growth of wireless communication demands for the antenna with low cost, low profile and with miniaturization. The microstrip antenna is the best candidate to fulfill such demand because of its low profile, conformal nature, easy to integrate with microwave integrated circuits. In last few years an extensive work has been carried out on microstrip antenna research with different modifications. Today, wireless hand held communication devices are used for multiple wireless applications. So it results in demanding an antenna which operated on multi frequency bands. For this reasons some techniques have been developed for the improvement of different performance parameter and for multi band operation. Some of the techniques to improve bandwidth, impedance matching, gain and multiband characteristics are like diamond shape slot, inverted L-shaped feed line, fractal patch , microstrip patch antenna array, stacked patch and different shaped slots[1].The microstrip antennas have the advantages like low profile, conformal nature, easy integration with MIC, less size and weight etc. Though Microstrip antennas suffers from disadvantages like low gain, less impedance bandwidth, low polarization purity etc. Several techniques have been developed for improving such disadvantages.

The idea proposed in this paper s to design \& optimize microstrip antenna with operates in dual band with multi resonant frequency in any of the two bands. To achieve this fractal geometry has been preferred to design an MSA. The fractal geometry has been used for designing multi band antenna with optimum size reduction. The presented work will focus on designing optimized dual band multi frequency microstrip antenna using fractal geometry. The fractal geometry has two important properties i.e. space filling and self-similarity which are absent in Euclidean geometries. Self-similarity of fractal geometry can be described as the geometry that is similar in all possible views of the observer. When the geometry is bisected into two equal halves on the vertical plane, the left plane becomes the folded image of the right plane and vice versa because of its selfsimilar property. Self-similarity provides additional flexibility in antenna design by allowing reduction of antenna by same factor or different factor horizontally and vertically. This property can be successfully applied to the design of multiband fractal antennas such as the Sierpinski Gasket Antenna. Fractal can be a line that can meander in such a way that it can effectively fill the entire sheet. It is observed that this space-filling property can lead to the miniaturization of antenna. The proposed antenna presents the application of fractal geometry to conventional antenna for optimization of its shape in order to reduce their overall size. This is due to the spacefilling property of fractal geometry which leads to curves that are electrically long, increasing the electrical size, and thus reducing antenna size[1]. 


\subsection{Generator}

\section{ANTENNA DESIGN}

An edge fed microstrip patch antenna is taken as the generator of Sierpinski Carpet Microstrip Patch antenna as shown in Fig. 1(a). There are three essential parameters for design of patch antenna i.e. resonant frequency $\left(\mathrm{f}_{\mathrm{r}}\right)$, dielectric material of the substrate $\left(\mathrm{E}_{\mathrm{r}}\right)$, and the thickness of substrate. Here $2.45 \mathrm{GHz}$ has been chosen as the resonant frequency. The dielectric material of the substrate selected for this design is FR-4 which has a dielectric constant (Er) of 4.4 and loss tangent equal to 0.019 with thickness of $1.59 \mathrm{~mm}$.

The width of the antenna[1] can be determined by:

$$
W=\frac{1}{2 f_{r} \sqrt{\mu_{0} \varepsilon_{0}}} \sqrt{\frac{2}{\varepsilon_{r}+1}}
$$

The effective dielectric constant[1] can be given by:

$$
\varepsilon_{\text {reff }}=\frac{\varepsilon_{r}+1}{2}+\frac{\varepsilon_{r}-1}{2}\left[1+12 \frac{h}{W}\right]^{-\frac{1}{2}}
$$

The dimension of the patch along its length is extended on each end by a distance $\Delta \mathrm{L}$ due to fringing effect[1], which is given by:

$$
\frac{\Delta L}{h}=0.412 \frac{\left(\varepsilon_{\text {reff }}+0.3\right)\left(\frac{W}{h}+0.264\right)}{\left(\varepsilon_{\text {reff }}-0.258\right)\left(\frac{W}{6 y}+0.8\right)}
$$

$$
L=\frac{1}{2 f_{r} \sqrt{\varepsilon_{\text {reff }}} \sqrt{\mu_{0} \varepsilon_{0}}}-2 \Delta L
$$

Where W,L ,h, $\mathrm{f}_{\mathrm{r}}, \mathrm{E}_{\mathrm{r}}, \mathrm{E}_{\mathrm{ff}}$ are the width of the patch, length of the patch, height of dielectric substrate, resonant frequency, dielectric constant of the substrate, effective dielectric constant respectively.

\subsection{Microstrip Antenna using Sierpinski Carpet Fractal Geometry}

Miniaturization techniques on fractal structure involve the process of removing some part of the basic structure. In this paper, compact size antenna is obtained by etching the rectangular microstrip patch as Sierpinski carpet of different iteration orders. In Sierpinski Carpet design, initially the rectangular patch is divided into nine smaller congruent rectangles and the central rectangle is removed. In further iteration, the remaining eight rectangles are divided into nine more congruent rectangles, removing central rectangle from each rectangle, and the similar procedure is followed for the other iteration. The schematic design of Sierpinski carpet of iteration 1, 2 , and 3 is shown in F ig. 1(b), Fig. 1(c), and Fig. respectively.

The iterative process in Sierpinski carpet design is based on the following rules[1]:

$$
\begin{gathered}
N_{n}=8^{n} \\
L_{n}=\left(\frac{1}{3}\right)^{n} \\
A_{n}=\left(\frac{8}{9}\right)^{n}
\end{gathered}
$$

Where $N_{n}$ is the number of rectangles covering the radiating material, $L_{n}$ is the length ratio, and $A_{n}$ is the ratio for the fractional area.

\subsection{Feeding Technique}

There are many feeding techniques that are used to feed microstrip antennas like microstrip line, coaxial probe, aperture coupled, and proximity coupled feed technique are used for feeding the microstrip antenna. The microstrip feed line feeding methods has been employed in this proposed antenna. 


\section{SIMULATION \& RESUlts Discussion}

The antenna was simulated in finite element method based Ansoft HFSS13 which is a high performance full-wave electromagnetic (EM) field simulator for arbitrary 3D volumetric passive device, having Microsoft windows graphical user interface. HFSS uses the principle of the Finite Element Method(FEM) for EM simulation by developing/implementing technologies such as tangential vector finite elements, adaptive meshing, and Adaptive Lanczos-Pade Sweep (ALPS)[1]. Initially, edge fed patch antenna was designed with the procedure mentioned in section 2.2. The Sierpinski Carpet iteration is performed up to $2^{\text {nd }}$ order. The dimensions of SCMPAs are shown in table-1.

All dimensions are in millimeters. The parameters mentioned in table-1 such as $\mathrm{Wp}, \mathrm{Lp}, \mathrm{Wa}, \mathrm{W}_{\mathrm{f}}, \mathrm{L}_{\mathrm{f}}$, are width of the patch, length of the patch, distance of the feed from edge of the patch, width of the feed line, and length of feed line respectively. The value of $\mathrm{E}_{\mathrm{r}}$ is 4.4 and material for dielectric substrate is FR4 epoxy.

Table: 1 DESIGN SPECIFICATIONS OF SCMPS

\begin{tabular}{|c|c|c|c|c|c|}
\hline Antenna & $\mathrm{W}_{\mathrm{p}}(\mathrm{mm})$ & $\mathrm{L}_{\mathrm{p}}(\mathrm{mm})$ & $\mathrm{W}_{\mathrm{a}}(\mathrm{mm})$ & $\mathrm{W}_{\mathrm{f}}(\mathrm{mm})$ & $\mathrm{L}_{\mathrm{f}}(\mathrm{mm})$ \\
\hline Generator & 37.25 & 28 & 10 & 1 & 10 \\
\hline Iteration 1 & 37.25 & 28 & 10 & 1 & 10 \\
\hline Iteration 2 & 37.25 & 28 & 10 & 1 & 10 \\
\hline
\end{tabular}

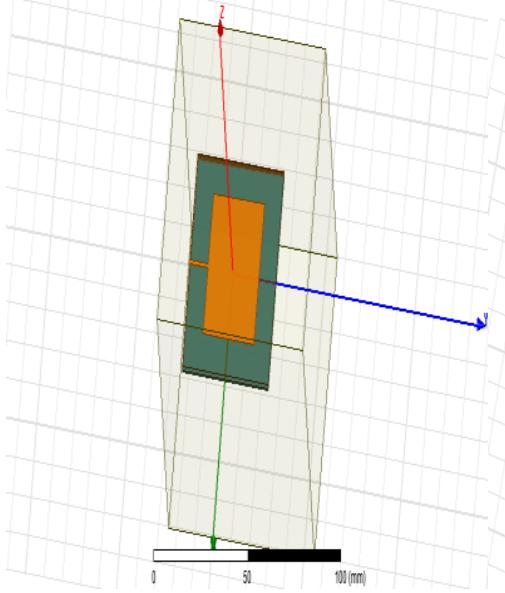

(a)

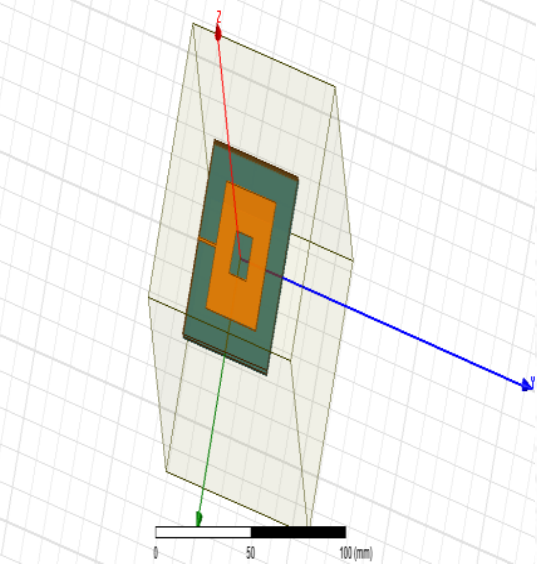

(b)

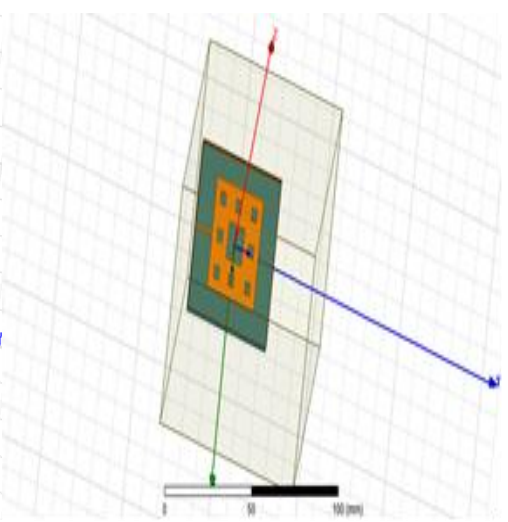

(c)

Fig. 1 (a) Generator , (b)Iteration-1, (c) Iteation-2

The Fig. 1(a),(b) and (c) illustrates the simple MSA, Sierpienski Carpet Iteration-1 and Iteration-2 respectively. The results for return loss and VSWR plot for above three antenna are illustrated in Fig.2 and in Fig.3 respectively.

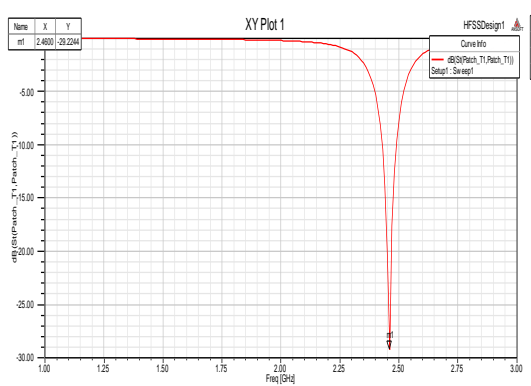

(a)

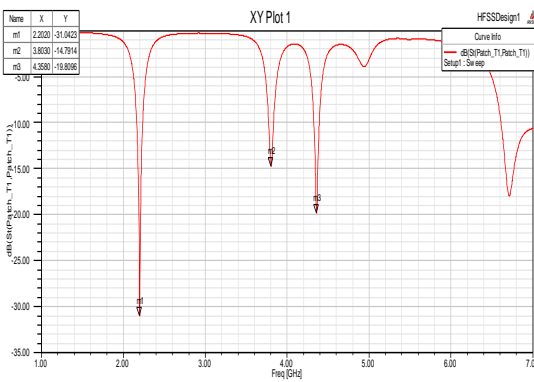

(b)

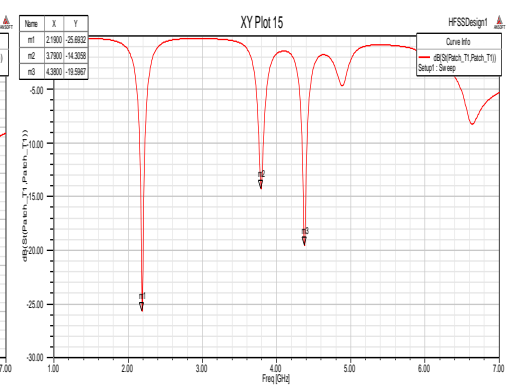

(c)

Fig. 2(a) Return Loss Of Simple MSA, (b) Return Loss Of Iteration-1, (c) Return Loss Of Iteration-2 


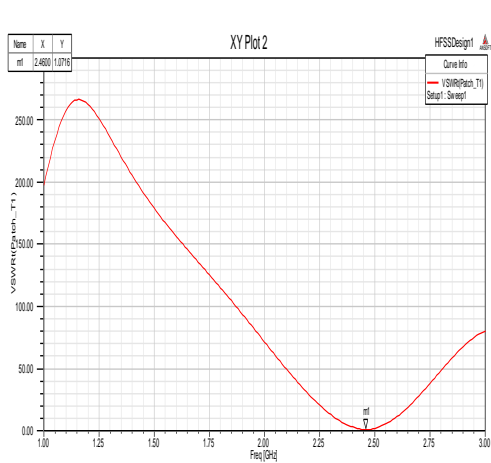

(a)

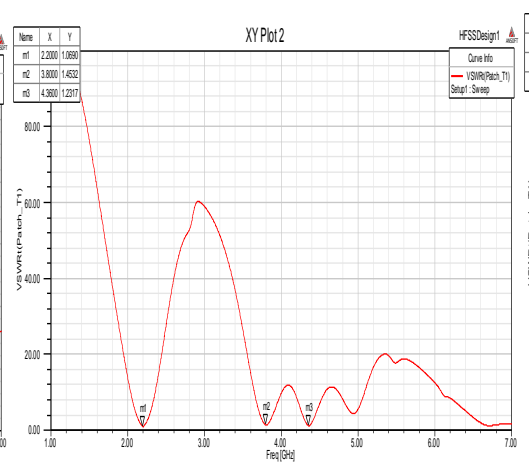

(b)

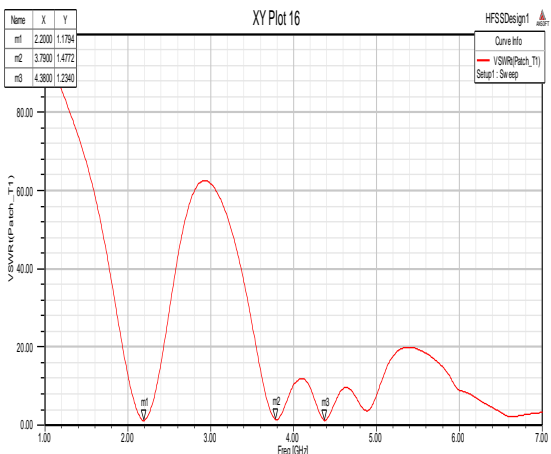

(c)

Fig. 3(a) VSWR Of Simple MSA, (b) VSWR Of Iteration-1, (c) VSWR Of Iteration-2

The results for the gain at phi $=0$ degree and phi $=90$ degree is illistrated in Fig. 4 (a), (b) and (c).

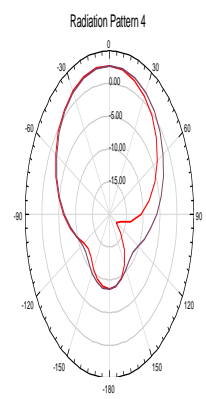

(a)

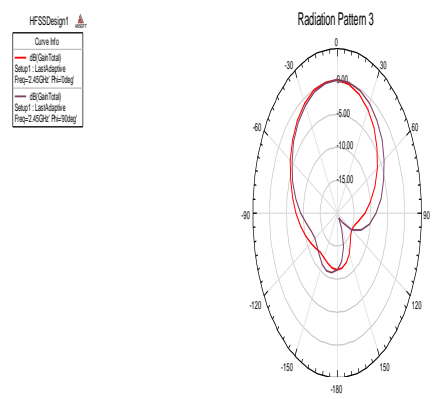

(b)

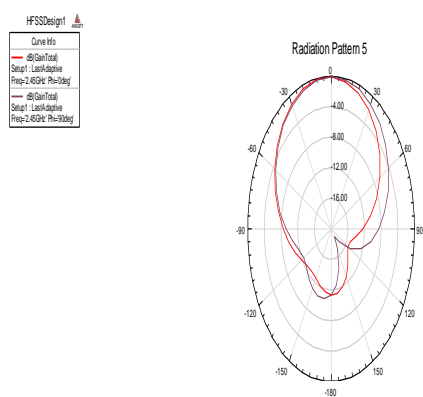

(c)

Fig. 4(a) Radiation Pattern Of Simple MSA, (b) Radiation Pattern Of Iteration-1, (c) Radiation Pattern Of Iteration-2

IV. RESULT SUMMARY

The Table 2 gives all the summarized results of the three proposed antennas.

TABLE 2: COMPARISON OF SIMPLE PATCH ANTENNA, $1^{\text {ST }}$ ITERATION, $2^{\text {ND }}$ ITERATION

\begin{tabular}{|c|c|c|c|c|}
\hline $\begin{array}{l}\text { Sr. } \\
\text { No }\end{array}$ & Antenna Type & $\begin{array}{l}\text { Simple } \\
\text { MSA }\end{array}$ & $\begin{array}{l}\text { MSA with } \\
\text { Iteration-I }\end{array}$ & MSA with Iteration-II \\
\hline 1. & $\begin{array}{c}\text { Resonant } \\
\text { Frequency } \\
(\mathrm{GHz})\end{array}$ & 2.46 & $\begin{array}{c}2.20 \\
3.80 \\
4.358\end{array}$ & $\begin{array}{l}2.19 \\
3.79 \\
4.38\end{array}$ \\
\hline 2. & $\begin{array}{l}\text { Returm Loss } \\
\qquad(\mathrm{dB})\end{array}$ & -29.2244 & $\begin{array}{l}-31.0423 \\
-14.7914 \\
-19.8096\end{array}$ & $\begin{array}{l}-25.6932 \\
-14.3058 \\
-19.5967\end{array}$ \\
\hline 2 & VSWR & 1.0716 & $\begin{array}{l}1.0577 \\
1.4454 \\
1.2385\end{array}$ & $\begin{array}{l}1.1095 \\
1.4772 \\
1.2340\end{array}$ \\
\hline 3 & Feed Impedance & $(49.86,-0.136)$ & $\begin{array}{c}(47.8,-1.91) \\
(71.66,-4.40) \\
(60.95,-3.03)\end{array}$ & $\begin{array}{c}(48.682,-5.74) \\
(72.659,-6.25) \\
(61.67,0.819)\end{array}$ \\
\hline 4 & $\begin{array}{l}\text { Co \& Cross } \\
\text { Polarization } \\
\text { (dB) }\end{array}$ & $-29.43 \mathrm{~dB}$ & $-19.05 \mathrm{~dB}$ & $20.625 \mathrm{~dB}$ \\
\hline 5 & $\begin{array}{l}\text { Patch Volume } \\
\left(\mathrm{mm}^{3)}\right.\end{array}$ & 52.65 & 46.8555 & 41.6748 \\
\hline
\end{tabular}

\section{ACKNOWLEDGEMENT}

The authors are thankful to Pro-Vice Chancellor of C.U. Shah University, Wadhwan City, for his unforgettable support and constant guidance and encouragement. The authors are also thankful to Pro-Vice Chancellor of C.U. Shah University, Wadhwan City for the permission to publish this work. 


\section{CONCLUSION}

In this paper the Siperpinski carpet geometry for fractal based microstrip patch antenna is implented. We get multiple resonant frequencies in various bands with optimum return loss and VSWR. So it is dual band multi frequency microstrip antenna. Also the size of the antenna can be reduced using fractal geometry up to $20.85 \%$. In future work higher order iterations can be taken and obtain result for that. Also we can fabricate this antenna and compare the results for the both

\section{PAPERS}

\section{References}

[1] Shrestha, S.; Jung-Jin Park; Sun-Kuk Noh; Dong-You Choi, "Design of 2.45 GHz Sierpinski fractal based miniaturized microstrip patch antenna," Communications (APCC), 2012 18th Asia-Pacific Conference on , vol., no., pp.36,41, 15-17 Oct. 2012.

[2] Shrestha, S.; Seung-Jo Han; Sun-Kuk Noh; Sunwoong Kim; Hyun-Bai Kim; Dong-You Choi, "Design of modified Sierpinski fractal based miniaturized patch antenna," Information Networking (ICOIN), 2013 International Conference on , vol., no., pp.274,279, 28-30 Jan. 2013.

[3] Douglas H.Werner;Suman Ganguly:“An Overview of Fractal Antenna Engineering Research” IEEE Antennas \& Propagation Magazine,Vol.45,No-1,February 2003.

[4] S. Suganthi, Member LACSIT; D.Kumar; S.Raghvan;"Design \& simulation of miniaturized multiband fractal antennas for microwave applications." International Journal of Information \& Electronics Enginering, Vol-2, N0.5, September-2012.

[5] Kulbir Singh,;Vinit Garewal; Rajiv Saxena; "A Fractal Antennas: A Novel miniaturization technique for wireless communication." International Journal of recent trends in Engineering, Vol-2, No.5,November-2009

[6] Rakesh Kumar; "Design \& simulation of dual \& triple band Fractal circular patch microstrip antenna for C-band application". International Journal of Engineering and Advanced Technology(IJEAT). ISSN:2249-8958,Volume-2,October 2012.

[7] Kuem c. Hwang;,Member IEEE; “A modified Sierpinski Fractal antenna for multiband application.” IEEE Antennas and wireless propagation Letters, Volume-6, 2007

[8] Rahim M. K A; Abdullah, N.; Abdul Aziz, M. Z A, "Microstrip Sierpinski carpet antenna design," Applied Electromagnetics, 2005. APACE 2005. Asia-Pacific Conference on , vol., no., pp.4 pp.,, 20-21 Dec. 2005.

\section{BOOKS}

[9] C. A. Balanis, Antenna Theory, 3rd ed. New York: John Wiley \& Sons Inc., 2005.

[10] Girish Kumar,K.P.Ray, Broadband Microstrip Antennas, Artech House antennas and propagation library,ArtechHouse,London,Boston 